\title{
Doğada Yapılan Sportif Etkinliklerde Çevresel Sürdürülebilirlik
}

\author{
The Environmental Sustainability in the Sporting Events in Nature
}

\author{
Funda KOÇAK' ${ }^{1}$, Velittin BALCI ${ }^{2}$ \\ ${ }^{1}$ Ankara Üniversitesi, Sağllk Bilimleri Enstitüsü, Beden Eğitimi ve Spor Anabilim Dalı, Ankara \\ ${ }^{2}$ Ankara Üniversitesi, Beden Eğitimi ve Spor Yüksekokulu, Ankara
}

\begin{abstract}
Özet: Bu çalışmanın amacı, doğada yapılan sportif etkinliklerde ekolojik çevre açısından karşılaşılan yanlış uygulamaları sürdürülebilirlik yaklaşımı açısından değerlendirmektedir. Çalışma amacına ulaşabilmek için, kapsam ve yöntem açısından durum analiziyle betimsel tarama yöntemi kullanılmıştır. Doğada yapılan spor etkinliklerine olan talebin artması doğal çevre üzerinde artan bir baskı oluşturmakta ve mikro ve makro düzeyde önemli çevre sorunlarına yol açmaktadır. Doğal alanlarda sürdürülebilirlik yaklaşımının benimsenmesi ve doğal çevrenin korunması, kapsamlı bir planlamayı ve planlanan alanda kaynakların doğru yönetimini gerektirmektedir. Sürdürülebilirlik açısından değerlendirildiğinde doğada yapılan spor etkinliklerinin daha özel yaklaşımlar gerektirdiği açıktır. Sonuç olarak, doğada yapılan spor etkinliklerinin gerçekleștirilmesinde sürdürülebilirlik yaklaşımının benimsenmesi hedeflenirken, çevresel sürdürülebilirliğin eğitim, kültür ve davranış biçimini de kapsadığı göz ardı edilmemelidir.
\end{abstract}

Anahtar Kelimeler: Doğal yaşam, Doğa, Sportif etkinlikler, Sürdürülebilirlik.

Abstract: The aim of this study is to evaluate wrong practices encountered with outdoor sports in terms of sustainability aproach that is widely accepted in many fields. Since stuational analysis is tried to be made in terms of aim, scope and metod in this study, descriptive scanning model was used. Increase in the demand for the sporting events in nature gradually constitutes an oppression on natural environment and caused environmental problems. Adopting sustainability approach in natural areas requires extensive planning for enabling the preservation of environment and visitors to have fun as well as increasing the interest in the sporting events in nature and correct management of sources in the planned areas. However, in planning works, it should not be neglected that each nature sport has unique features and therefore it may require specific approaches. In conclusion, in aiming at determining sustainability approach for realization of outdoor activities, it will be important to adopt not only as environmental sustainability but also as participation, social benefit and awareness, education, cultural and behavior pattern.

Keywords: Natural life, Nature, Sportif events, Sustainability.

\section{Giriş}

Günümüzde artan kentlileşme ile kentsel mekanlardaki mevcut rekreasyon ve spor alanlarıyla/tesisleriyle hareket yaşantısını sürdürmeye çalışan kent insanı giderek artan bir istekle, bu suni mekanlardan uzaklaşmayı isteyerek doğaya açılmayı yeni bir etkinlik biçimi olarak benimsemektedir. Bu istek içinde rutinden kaçış, gürültüden ve kentsel kirlilikten uzaklaşma vb. gibi birçok nedenin yanında, yeni heyecan ve gerilim arayışları da göze çarpmaktadır. Doğada yapılan sportif etkinlikler yukarıdaki içerikten dolayı da gittikçe artan bir arz ve talep yaratmaktadır. $\mathrm{Bu}$ talebin artmasında ulaşım fırsatlarının artması, etkinlikler için farklı malzeme üretimi ve pazarlanması da dikkate değer unsurlardır.

Ormanlık ve dağlık alanlar nitelik ve nicelik açısından en fazla öneme sahip açık hava spor kaynaklarının başında gelmektedir. Bu nedenle her türlü doğa sporu etkinlik alanlarında sürdürülebilirlik yaklaşımında bu alanları öncelikle dikkate almak önemlidir. Çünkü bu alanların ekolojikdengenin sağlanmasında ve bozulmasında anahtar rolü, sürdürülebilirlik kavramıyla örtüşmektedir. Kullanımdan doğan atıklar ve kirlenme, doğanın kendini yenileme yeteneğini ortadan kaldırmaktadır. Çünkü çevre kirliliğinin oluşmasında temel neden; doğanın insan etkinlikleriyle ortaya çıkan atıkları kendiliğinden giderme yeteneğinin bozulmasıdır (Çevik, 1999).

Ekonomi, turizm, mimari, tarım gibi pek çok alanda sıkça kullanılan sürdürülebilirlik kavramı, toplumun sosyal, kültürel, bilimsel, doğal ve insan kaynaklarının tümünün etkin kullanımını sağlayan ve buna saygı duyma temelinde dayanan katılımcı bir süreç olarak tanımlanmaktadır (Gladwin vd., 
1995). Sürdürülebilirliğin esası; doğal kaynakların verimli kullanılmasına, atıkların azaltılmasına, kaynakların geri dönüşümünün sağlanmasına, gelecek nesillerin ihtiyaçlarına cevap verecek ve çevrenin sürekli şekilde korunmasına dayanmaktadır (Nemli, 2007).

Pils vd.'ne (1996) göre doğada yapılan etkinlikler sonucunda doğaya verilen zararlar gürültü kirliliği, su kirliliği, çöp üretimi ve bunların uzaklaştırılmasında karşılaşılan sorunlar, kanalizasyon sorunları, kış sporları alanlarındaki binalardan dolayı görsel kalitenin bozulması, tırmanış için kayaların işaretlenmesi ve boltlanması, aşırı kullanıma bağlı olarak: patikaların bozulması, taşıt kullanımı sonucu oluşan hava kirliliği, bitki örtüsünün tahribi şeklinde sıralanabilir (Somuncu, 2004). $\mathrm{Bu}$ nedenle her türlü doğa sporu etkinlik alanlarında sürdürülebilirlik yaklaşımından hareketle bir dizi önlemler alınmalıdır.

Sınırlı sayıdaki sporda çevresel sürdürülebilirlik literatürüne katkı yapabilecek bu çalışmada, doğada yapılan sportif etkinliklerin temel elemanlarını tartışarak kapsamını belirlemek, doğada yapılan sportif etkinliklerin çevreye üzerindeki olumsuz etkilerini ortaya koymak ve sürdürülebilirlik yaklaşımı açısından değerlendirmek amaçlanmıştır.

\section{Doğada Yapılan Sportif Etkinlikler}

Doğada yapılan sportif etkinler "doğa sporları", "açık alan rekreasyonu”, "macera sporları", "macera rekreasyonu", olmak üzere içinde bulundurdukları risk faktörlerine ve kullanılan yardımcı unsurlara bağlı olarak değişik isimlerle sınıflandırılmıştır.

Doğa yürüyüşü, kampçılık, balıkçılık, kano, kayak, at biniciliği, golf, su kayağı, motor sporları, hava sporları gibi geniş etkinlik yelpazesi yoluyla katılımcıların doğal çevre ile etkileşime girmelerine açı alan rekreasyonu adı verilmektedir (Cordes and İbrahim, 1999).

Doğa sporları ise Priest ve Gass'a (1997) göre açık alan rekreasyonun sadece insan gücü ile oluşturulmuş halidir. Başka bir tanıma göre ise doğa sporları insanın sahip olduğu bilgi, beceri ve kondisyonu ile hiçbir motor ve hayvan gücü desteği alınmaksızın, doğanın var olan potansiyel zorluk ve risklerine karşı mücadele etme ve yaşamı sürdürme etkinlikleri şeklinde ifade edilmektedir (Uluocak ve Köksal, 1998). Kaya tırmanışı, dağcılık, mağaracılık, yürüyüş, kampçılık, kayak, su altı sporları, oryantiring, bisiklet, yelken, kano, akarsu kapalı kanosu, rafting gibi doğal alanda yapılan pek çok sporu ve etkinliği kapsamaktadır (Broadhurst, 2001).

Doğa sporları etkinlikleri, motor gücü desteği alan moto-kros, kar motoru, araba yarışı, motorlu tekne gibi etkinlikleri, benzer şekilde hayvan gücü desteği alan; ata binme, köpekli kızak gibi etkinlik alanlarını içermemektedir. Tüm bunlar kesinlikle bir açı alan rekreasyonu olmasına karşın, doğa sporları etkinliklerine genelde eşlik eden insan gücü desteğinin kısıtlı, doğal çevreyle verilen en az etki felsefesinden uzaktırlar (Dinç, 2008). Demirhan'da (2003) yapmış olduğu çalışmada yüksek dağ tırmanışı, kaya tırmanışı, oryantiring, mağaracılık, dăg bisikleti, kürek, yüzme, sörf, sualtına dalma, yelken, rafting, alp kayağı, kuzey kayağı, tur kayağı, snowboard, paraşüt, hand glading, cliff jumping ve yamaç paraşütünü doğa sporları olarak ele almıştır. Buradan hareketle doğa sporları insanın sahip olduğu bilgi, beceri ve kondisyonu ile, hiçbir motor ve hayvan gücü desteği alınmaksızın, doğanın var olan potansiyel zorluk ve risklerine karşı mücadele etme ve yaşamı sürdürme etkinlikleri olarak tanımlanabilir.

Macera rekreasyonu ise sonuçların kesin olmadığı ve bu sonuçların katılımcılarca etkilendiği, genellikle doğal bir çevrede gerçekleştirilen, algılanan veya gerçekleşen tehlike elemanlarını kapsayan rekreasyonel faaliyetlerdir (Ewert and Hollenhorst, 1995).

Tüm bu tanımlardan sonra açık alan rekreasyonu, doğa sporları, macera rekreasyonu ve macera sporlarını içe alan doğada yapılan sportif etkinlikleri havada, karada ve suda yapılanlar şeklinde sınıflayabiliriz. Bu başlıkların altında yer alan etkinliklerin çeşitleri gün geçtikçe artmaktadır. Yapılan bu sınıflandırmaya göre doğada yapılan sportif etkinlikler Tablo 1'de gösterilmiştir. 
Tablo 1. Doğada yapılan sportif etkinlikler (Bentley vd., 2001).

\begin{tabular}{|c|c|}
\hline Etkinlik Sınıflaması & Etkinlik Ad1 \\
\hline \multirow{7}{*}{ Havada Yapılanlar } & Hand gliding \\
\hline & Balon \\
\hline & Gliding \\
\hline & Paraşüt \\
\hline & Paragliding \\
\hline & Gezinti turları (küçük uçak, helikopter) \\
\hline & Helikopterli bungy jumping \\
\hline \multirow{14}{*}{ Suda Yapılanlar } & Su alt1 raftingi \\
\hline & Mağaracılık \\
\hline & Tüplü-tüpsüz dalış \\
\hline & Gemiyle seyahat \\
\hline & Jetski \\
\hline & Jet botu \\
\hline & Parasailing \\
\hline & Rafting \\
\hline & Nehir ve deniz kayağ 1 \\
\hline & Kano \\
\hline & Nehir sörfü-nehir kızağ1 \\
\hline & Su kayağ1 \\
\hline & Rüzgar sörfü \\
\hline & Balıkçılık \\
\hline \multirow{15}{*}{ Karada Yapılanlar } & Kros kayağ \\
\hline & Yamaç kayağı \\
\hline & Helikopterli kayak \\
\hline & Kayaklı yürüyüş \\
\hline & Trekking \\
\hline & Araç safarisi \\
\hline & Bungy Jumping \\
\hline & Bisiklet \\
\hline & Buzul yürüyüşü \\
\hline & Ata binme \\
\hline & Avcılık \\
\hline & Dağcıllk \\
\hline & Oryantiring \\
\hline & İpli iniş \\
\hline & Kaya tırmanışı \\
\hline
\end{tabular}

\section{Sürdürülebilirlik Kavramı ve Tanımı}

"Sürdürülebilirlik” kavramı ilk kez 1970'li y1llarda kullanılmasına rağmen "1987 y1lında Birleşmiş Milletler sponsorluğundaki Dünya Çevre ve Kalkınma Komisyonu'nun (WCED) yayınladığı "Ortak Geleceğimiz" raporunda resmi olarak tanımlanmıştır. Rapor geneli itibariyle dünyayı tehdit eden çevresel sorunlar ve bu sorunların çözümü için ulusal ve uluslararası düzeyde yapılması gerekenlerin sunumu niteliğindedir. Üzerinde çokça tartışılmakla beraber, bu raporda yer alan sürdürülebilir gelişme tanımı, dünyanın geleceği konusunda genel bir görüş getiren oldukça kullanışlı bir tanımdır: sürdürülebilirlik raporda "günümüzün gereksinimlerini, gelecek nesillerin kendi gereksinimlerini karşılayabilme yeteneklerinden ödün vermeden karşılayan kalkınma" olarak tanımlanmıştır (WCED 1987).

Raporda sürdürülebilir gelişme için hedefler şu şekilde sıralanmıştır:

- Önemli çevre ve gelişme sorunlarını yeniden incelemek ve bunlarla ilgili gerçekçi önerilerde bulunmak,

- $\mathrm{Bu}$ sorunlarla ilgili gereken düzenlemeleri gerçekleştirebilecek politikalar oluşturmaya katkı sağlayacak, uluslararası işbirliği yöntemleri geliştirmek, 
- Gönüllü kuruluşların, bireylerin, iş çevrelerinin, enstitülerin ve hükümetlerin konuya ilgisini artırmak

- İnsan ihtiyaçlarının karşılanması,

- Bölge halkının ve turistlerin bugünkü gereksinimleri karşılanırken, geleceği korumak ve değerini arttırmaktır.

Bu hedeflere ulaşırken, kültürel bütünlüğü sağlayan, biyolojik çeşitliliği arttıran ve canlıların yaşamını destekleyen, ekonomik, sosyal ve estetik ihtiyaçları karşılayan kaynakların yönetiminin planlaması, oldukça önem kazanmaktadır (Kaya and Smardon, 2001).

Mazurkiewicz (2005)'e göre ise çevresel sürdürülebilirlik kurum ve kuruluşların üretimlerinde ve tesis planlamalarında, atıkları ve zararlı salınımları en aza indirmek, kaynakların kullanımında verimliliği artırmak ve ülke kaynaklarından gelecek nesillerin üst düzeyde yararlanmalarını sağlamak olarak tanımlamıştır.

Sürdürülebilirlik kavramının çevresel yönü insan faaliyetlerinin içinde yer aldığı doğal çevre ile ilişkilidir. Yine Ortak Geleceğimiz raporuna göre (WCED, 1987) "eğer ihtiyaçlar sürdürülebilir bir çevrede karşılanacaksa, dünyanın doğal kaynakları korunmalı ve güçlendirilmelidir". Bu nedenle enerjinin ve yenilenemeyen malzemelerin küresel ölçekte hızla tüketimi karşısında, kaynak kullanımında yeni bir yaklaşım oluşturulması sürdürülebilirliğin diğer bir temel bileşenidir. Bu yeni yaklaşım, günümüzde sürdürülebilirlik stratejileri olarak karşımıza çıkmaktadır. Sürdürülebilir kaynak kullanımın temek stratejileri; sürdürülebilirliğin 3R'si olarak da ifade edilen azaltma (reduction), yeniden kullanım (reuse) ve geri dönüşümdür (recycling) (Goldsmith, 2000). Malzeme kullanımını ürün yapımıyla ilgili sanayilerin atıklarını azaltmak, daha az paketleme yapmak ve var olan ürünleri koruyarak ömürlerini uzatmak azaltma stratejisinin temelini oluşturmaktadır. Yeniden kullanım stratejisi ise bir ürünün aynı döngü içinde tekrar kullanımını ön görmektedir. Cam şişelerin toplanması, içecek dağıtıcısında yıkanması ve içecek için tekrar kullanılması, yeniden kullanım stratejisi için örnek oluşturmaktadır. Geri dönüşüum stratejisi ise, ürünlerin atık malzemelerden tekrar üretilmesi temeline dayanmaktadır. Atık kağıtların yeni kağıt ürünlerine dönüştürülmesi, atık şişelerin tekrar cam haline dönüştürülmesi geri dönüşüm stratejisine örnek olarak verilmektedir (Wheeler, 2004). Sürdürülebilirlik stratejileri çevresel sürdürülebilirliği sağlama oldukça önemlidir ve etkin bir biçimde kullanılması gerekmektedir.

Sürdürülebilirlik kavramı 1980’lerden itibaren uluslararası çevresel tartışmalarda kalkınma, uygulamalı bilim, çevresel ve uluslararası politika alanlarında çok yönlü olarak incelenen ve odak noktası haline gelmiş olan bir kavram olmasına rağmen kalkınma stratejilerinin sonuçları konusunda ya da anlamı ve tanımı üzerine çok az fikir birliği sağlanmış bir kavramdır (Carvalho, 2001). Sürdürülebilirlik sadece çevre korumanın ön plana çıktığı bir gelişme anlayışını ifade etmemekte, gelişmeye ilişkin bütün ekonomik, malî ve ticari politikaların; ekonomik, sosyal ve çevre ile ilgili açılardan uyumlaştırıldığı bir süreç olarak karşımıza çıkmaktadır (Nemli, 2007).

Yukarıda görüldüğü gibi çok boyutlu bir kavram olan sürdürülebilirliğin en çok önem taşıyan yönünün çevre ile ilgili olduğu ifade edilebilir. Çünkü doğal çevre üzerindeki yaratılan herhangi bir olumsuzluk bir daha geri dönülemez şekilde tüm canlıların yaşamını tehdit etmektedir.

\section{Doğada Yapılan Sportif Etkinliklerin Doğal Çevre Üzerindeki Etkileri}

İnsan çevresiyle uyum içerisinde ve belli bir dengenin sağlanmasıyla yaşamını sürdüren, ancak bazı durumlarda dengeyi bozabilen bir varlıktır. İnsan ile çevresi arasındaki dengeyi sağlayan koşullar bozulmaya başlayınca, insanların gerekli bir takım önlemleri alma zorunluluğu ortaya çıkmaktadır. Çünkü doğada yapılan sportif etkinliklerin ham maddesi olan doğal çevrenin olumsuz etkilenmesi bu sporların sürdürülebilirliğini de tehlikeye sokmaktadır.

Doğa sporları etkinlikleri de, etkinlik çeşidine göre, doğal alanlarda bir çok ekolojik bozulmalara neden olabilmektedir. Bu olumsuz çevresel etkiler Tablo 2'de gösterilmiştir. 
Tablo 2. Doğal alan kullanımının çevre üzerindeki etkileri (Altan, 1983'den aktaran Kuntay, 2004)



Tablo 2'ye bakıldığında doğada yapılan etkinliklerin kendilerine özgü ihtiyaçlarından kaynaklanan pek çok olumsuz çevresel etkisi ortaya çıkmaktadır. Bu etkiler doğal alanlarının kullanım süresine, sıklığına ve yapılan yanlış uygulamalara göre değişik boyutlarda olmaktadır.

Ewert'da (1999) yapmış olduğu çalışmada doğada yapılan etkinliklere katılanların doğal alanlarda meydana getirebilecekleri etkilerin özelliklerini aşağıda belirtildiği şekilde irdelemiştir:

- Etkiler değişik boyutlardadır: Doğada yapılan etkinliklere katılanların çevreye verebilecekleri etkilerin boyutları farklıdır. Bu farklılık makro ya da mikro düzeyde olabilir.

- Kullanım etki yaratır: Tüm eğitsel çabalara rağmen insanlar, doğal alanlarda gerçekleştirdikleri etkinlikler sırasında çevreye dolaylı ya da dolaysız pek çok etkide bulunurlar. Kullanıcıların çevreye çöp atması gibi davranışlar dolaysız etki olarak değerlendirilirken kullanıcıların "ekolojik maliyetleri” dolaylı etki olarak değerlendirilir.

- Kullanım etkileri zamana bağlıdır: Birçok durumda doğal alan kullanımından kaynaklanan olumsuz etkilerin büyük bir bölümü kullanımın başlangıcında gerçekleşir.

- Faaliyetlerinin türleri önemlidir: Doğal alanlarda faaliyetlerin türü, kullanıcı sayısı kadar önemlidir. Ateş yakmak, ata binmek gibi faaliyetler bazı alanlarda olumsuz etkileri nedeniyle sinırlandırılmaktadır. 
Tablo 3. Rekreasyon amaçlı doğal alan kullanımının doğal yaşam üzerindeki etkileri (Ewert, 1999).

\begin{tabular}{|c|c|}
\hline Doğal Yaşam Üzerine Etkiler & Etkinin Nedenleri \\
\hline \multirow{5}{*}{ Habitatın Değişmesi } & Oyun rotalarının kalabalıklığ1 \\
\hline & $\begin{array}{l}\text { Habitatın değişmesinin yaban hayatı davranışlarında } \\
\text { meydana getirdiği değişiklikler }\end{array}$ \\
\hline & Hayvan yuvaların ve beslenme alanlarının yok edilmesi \\
\hline & Su/toprak kimyasinda bozulmalar \\
\hline & Barınma alanlarının yok edilmesi \\
\hline \multirow{7}{*}{ Rahatsiz Etme } & Besleme \\
\hline & Fotoğraf ve film çekme \\
\hline & Barınma alanları \\
\hline & Yuvaların, beslenme alanlarının bulunması \\
\hline & Otomobillerin etkisi \\
\hline & Kar araçları/bisikletlerin etkisi \\
\hline & İnsanların ve evcil hayvanların varlığı \\
\hline \multirow{4}{*}{ Kirlilik } & Plastik \\
\hline & Yağ/petrol ürünleri \\
\hline & Çeşitli yabancı yiyeceklerle hayvanları beslemeye çalışmak \\
\hline & Tortullaşmanın artması \\
\hline \multirow{5}{*}{ Toplayıcılık } & Toplama \\
\hline & Avlanma \\
\hline & Tuzağa düşürme \\
\hline & $\begin{array}{l}\text { Balıkçılık } \\
\text {-satı̧ amaçlı } \\
\text {-beslenme amaçlı } \\
\text {-rekreasyonel amaçlı }\end{array}$ \\
\hline & Yem ya da predatör türlerin kaybolması \\
\hline
\end{tabular}

Son yıllarda tüm dünyada dağcllık ve dağ turizmine olan ilgi artmaktadır. Somuncu (2004)'ya göre hassas ekosistemler olan dağlık alanlardaki doğal kaynaklar doğru kullanılmadığı takdirde doğal çevre zarar görmektedir. Değişik ülkelerdeki dağlarda bunun pek çok örneği gözlenmektedir. Başta Himalayalar ve Alpler olmak üzere yüksek dağlardaki doğal çevre sorunları ciddi boyutlara ulaşmıştır. Dağlarda ortaya çıkan bu sorunların ana kaynağı öncelikle bu alanları turizm/rekreasyon amaciyla kullanan dağcıların kendisi, ikinci olarak da turizm hareketinin içinde yer alan diğer kişi ve kuruluşlar olarak görülmektedir. Buradan hareketle dağcllık ve dağ turizminin çevresel yönleri ve iyi bir planlama yapılmadığında çevre üzerindeki etkileri ayrıntılı olarak görülmektedir.

Spor faaliyetlerinin ormanlara verdiği diğer bir zarar da, doğada doğa sporları faaliyetleri (hiking, trekking, kampçılık vb.) sırasında çok sık görülen ateş kullanımı dikkatsizliği ve bunun yol açtı̆̆ orman yangınları biçiminde kendini göstermektedir (Aslan ve Aktaş, 1994). Bunun yanında özellikle araçların düzensiz olarak orman alanı içinde dolaşmaları ve gerçekleştirilen yoğun doğa sporu etkinlikleri üst toprağı sıkıştırarak toprak geçirgenliğini azaltması nedeniyle doğal ortamın doğrudan veya dolaylı olarak tahribine neden olmaktadır. Kıyı bölgelerde ve göl kenarlarında, yoğun etkinlik nedeniyle sahil kumları, otomobil ve insan çiğnemeleri sonucu erozyon başlatmakta ve kumlar tarım arazilerine akarak, onların verimsizleşmelerine neden olmakta, aynı zamanda göllerde olumsuzluklara yol açmaktadır. 
Tablo 4. Dağcılık ve dağ turizminin etkileri (Somuncu, 2004).

\begin{tabular}{|c|c|}
\hline \multirow{2}{*}{$\begin{array}{c}\text { Dağccllık } \\
\text { aktivitelerinin } \\
\text { kendisini tehdit }\end{array}$} & $\begin{array}{l}\text { Tırmanış rotalarının önceden belirlenerek işaretlenmesi veya kayaların boltlanması, tırmanıcıların } \\
\text { kendi arzuları doğrultusunda tırmanışlarını engeller. }\end{array}$ \\
\hline & Erozyon patikaları tahrip eder. \\
\hline \multirow{5}{*}{$\begin{array}{l}\text { Biyolojik } \\
\text { çeşitliliği tehdit }\end{array}$} & Kaya tırmanıcıları nadir kuşların yuvalarına zarar verebilir. \\
\hline & Kalabalık ziyaretçiler yolları üzerindeki hayvanları ürkütebilir. \\
\hline & Kitlesel doğa yürüyüşleri ormansızlaşmayı hızlandırır. \\
\hline & Kayaklı dağcılık kritik kış döneminde hayvanları ürkütebilir. \\
\hline & Geleneksel tarımsal faaliyetlerin sürdürüldüğü alanlar değișime uğrar. \\
\hline \multirow{3}{*}{$\begin{array}{l}\text { Ulaşım } \\
\text { problemleri }\end{array}$} & Genelde trafik artar-dağcılar tırmanmak için yaşadıkları yerden uzaklara seyahat ederler. \\
\hline & Dağcılık alanlarında trafik artar çünkü eğilim destinasyona mümkün olduğunca yaklaşmaktır. \\
\hline & Park yeri problemleri ortaya çıkar. \\
\hline \multirow{3}{*}{ Kirlilik } & Çöp miktarı artar. \\
\hline & Su kirliliği artar. \\
\hline & Gürültü kirliliği artar. \\
\hline \multirow{5}{*}{$\begin{array}{l}\text { Görsel değerleri } \\
\text { tehdit }\end{array}$} & Dağ kulübeleri, sığınaklar vb. üniteler \\
\hline & Teleferikler ve yollar \\
\hline & Dağcılık "dağlara tırmanma sporu” olarak çoğu yerel kültüre tümüyle yabancıdır \\
\hline & Ziyaretçiler kendi tüketim alışkanlıklarını ve yaşam biçimlerini dağlara getirirler \\
\hline & Yerel sosyal yapıda değişiklik ortaya çıkar. \\
\hline \multirow{3}{*}{$\begin{array}{l}\text { Dağların manevi } \\
\text { değerlerini tehdit }\end{array}$} & $\begin{array}{l}\text { Dağların pek çok yerel kültürdeki dinsel rolüne, insanların tabularına ve inançlarına saygı } \\
\text { göstermeme }\end{array}$ \\
\hline & $\begin{array}{l}\text { Ziyaretçi kalabalıklığının kişiler için yaban hayatı ya da bozulmamış doğadan manevi yararlanmayı } \\
\text { engellemesi }\end{array}$ \\
\hline & Dağları satın alınabilen bir madde gibi düşünme \\
\hline
\end{tabular}

\section{Doğada Yapılan Etkinliklerde Sürdürülebilirliğin Sağlanması}

Doğaya yapılan sportif etkinliler doğal eko-sistemleri doğrudan etkileyebilmektedir. Bu tür etkinlikler planlanırken hedeflenen sonuç, genel olarak sporcuların ve katılımcıların en yüksek derecede doğadan faydalanmalarını sağlamak, aynı zamanda da eko-sistemlerin zarar görmesini sinırlandırmak ve hatta önlemektir (Anonim, 2008). Sürdürülebilir düzenleme, doğal çevrenin korunmasında önemli kazançlar sağlarken ve doğal alanlarının kullanım potansiyelini de artıracaktır. Çevre ve sürdürülebilir gelişim bakış açısıyla değerlendirildiğinde, doğada yapılan etkinliklerin planlanmasında uyulması gerekenler genel öneriler halinde şu şekilde sıralanabilir:

Etkinlik planı yapılmalı: Ziyaret edilecek bölgede uyulması gereken kurallar bilinmelidir. Ani hava değişimleri, acil durumlar ve tehlikeli durumlar için hazırlıklı olunmalıdır. Etkinlik süresinde tamamlanmalı, gereksiz yere uzatılmamalıdır. Atık miktarını en aza indirmek için ambalajı tekrar kapatılabilen besinler tercih edilmelidir. Ziyaret edilecek alandaki kamp kuralları ve koşulları önceden kontrol edilmelidir. Önceden izin alınıp alınmaması gerektiği bilinmelidir.

Grup büyüklüğüne karar verilmeli: Bazı koruma kapsamındaki bölgelerde aynı anda sınırlı sayıda insanın ziyareti kabul edilir. Doğada yapılan bir etkinlik için aynı alanda önerilen grup büyüklüğü en fazla sekiz kişiden oluşmalıdır (Anonymous 2009).

Fauna korunmall: Hayvanlar uzaktan izlenmeli, dokunulmamalı ve kovalanmamalıdır. Hayvanlar beslenmeye çalışılmamalıdır. Çünkü hayvanlar beslemek onların sağlıklarına zarar verip davranışlarını değiştirirken, predatörlerine ve diğer tehlikelere karşı onları ortaya çıkarmaktadır. Gıdalar, erzaklar ve güvenli bir biçimde depolanarak hayvanların onlardan uzak durması sağlanmalıdır. Çiftleşme ve yuvalama ve yavrularını besleme gibi yaban hayatı için hassas olan dönemlerde onları özellikle rahatsız etmekten kaçınılmalıdır.

Habitat korunmalı: Tek sıra halinde yürüyüş, binicilik, araba kullanımı gibi etkinlikler nedeniyle ortaya çıkan erozyondan bitkilerin ve çamurdan oluşmuş bile olsa patikaların tahribatından kaçınılmalıdır. Kültürel, tarihi yapılar ve eserlere dokunulmamalı böylece geçmiş korunmalıdır.

Taşlar, bitkiler ve diğer doğal nesneler nasıl bulunduysa öyle bırakılmadır. Sabunlar, deterjanlar, petrol, yağlar, böcek ilaçları ve güneş koruyucuları gibi her türlü kimyasal maddenin suyollarını kirletmesinden kaçınılmalıdır (Anonim, 2008). 
Suyolları ve göller korunmalı: Akarsu kenarları korunmalı, kamp alanı akarsulardan ve akış yönlerinden en aza 50 metre uzakta olmalıdır. Duş alırken ya da bulaşıkları yıkarken, su akarsulardan ve akış yönlerinden uzağa taşınmalı ve az miktarda toprakta çözünebilen sabun kullanılmalıdır. Hijyen alanı olarak göl ve suyollarından en az 100 metre uzaklıktaki alanlar kullanılmalıdır.

Kamp yeri seçimi: Kamp alanında çadır kurmak için düz ve dayanıklı bir yüzey seçilmelidir. Hassas çimlerin ya da yeniden canlanması uzun zaman alacak habitatların bulunduğu alanlara çadır kurmaktan kaçınılmalıdır.

Atıkların uzaklaştırılması: Kamp yerinden ayrılmadan önce kamp alanı ve etkinlik alanları incelenmeli çöpler toplanmalıdır. Kamp alanından ayrılırken, alanın ilk geldiğinizden günden daha temiz olmasına dikkat edilmelidir. Eğer tuvalet yoksa katı atıkları su alanlarından ve akış yönlerinden en az yüz metre uzakta $15 \mathrm{~cm}$ derinliğe gömmek gereklidir. Hijyen ürünleri kesinlikle toprağa gömülmemelidir (Fresque and Plummer, 2009).

Kamp Ocakları ve Ateş Kullanımı: Ziyaret edilen bölge koşulları aktive öncesinde kontrol edilmeli ateşe izin verilip verilmediği öğrenilmelidir. Açık bir ateş yerine yemek pişirmek için gaz ocağı ya da hafif yakıtlarla çalışan ocaklar kullanılmalıdır. Açık ateş kullanılacaksa bir ateş simidi ya da çukuru kullanılmalıdır. Ateş küçük tutulmalı, bitkilerden ve çadırlardan uzakta tutulmalıdır. Kamp çevresinde canlılar için hayati önemi olan ölü odun parçaları toplanmamalı, kamp yerinden ayrılmadan önce yakılan ateş mutlaka söndürülmelidir. Yangın tehlikesi olduğundan ateş kesinlikle aydınlatma olarak kullanılmamalıdır.

Başkalarına Saygılı Olma: Sizin hakkınız olduğu kadar diğer ziyaretçilerinde açık alanlarda eğlenceli vakit geçirmeleri için onlara saygılı olun. Açık alanlara ve diğer kullanıcılara karşı saygılı olun. Yüksek ses ve gürültüden kaçının. Doğanın sesinin etrafa hakim olmasına izin verin.

Doğada yapılan sportif etkinliklere katılım bugün olduğu gibi, gelecekte de büyük kitleler halinde devam edecektir. Doğal alanların bu kullanımdan olumsuz etkilendiği de bilinen bir gerçektir. Doğa da yapılan sportif etkinliklerde sürdürülebilirlik uygulamaların hayata geçirilmesi bu açıdan önem taşımaktadır. Doğada yapılan etkinliklerde sürdürülebilirliğin sağlanmasında yukarıda sıralanan önemli noktalar ilkeler haline getirilerek bütün etkinlik katılımcılarında farkındalık sağlanmalıdır. $\mathrm{Bu}$ ilkeler özetlenerek Tablo 5'de gösterilmiştir.

Tablo 5. Doğada ekolojik ayak izi bırakmama ilkeleri ve yapılması gerekenler (Fresque ve Plummer, 2009).

\begin{tabular}{|c|c|}
\hline $\begin{array}{l}\text { Doğada Ekolojik Ayak İzi Bırakmama } \\
\text { İlkeleri }\end{array}$ & Yapılması Gerekenler \\
\hline Etkinlik öncesi planı hazırlanmalı & $\begin{array}{l}\text { - küçük gruplar halinde seyahat edilmelidir. } \\
\text { - kullanım süresi sınırlandırılmalıdır. } \\
\text { • sadece önemli ihtiyaçlar doğaya götürülmelidir. (örneğin; ekipman } \\
\text { yiyecek, giyecek) }\end{array}$ \\
\hline $\begin{array}{l}\text { Gezinti ve kamp için dayanıklı yüzeyler } \\
\text { seçilmeli }\end{array}$ & $\begin{array}{l}\text { - mevcut kamp alanları ve yollar kullanılmalıdır. } \\
\text { - alan ihtiyacı minimuma indirilmelidir (yemek yapma, çadır kurma vb. } \\
\text { - su kaynaklarının uzağında kamp kurulmalıdır. }\end{array}$ \\
\hline Atıkların uzaklaştırılması & - tüm atıklar paketlenmelidir. \\
\hline Bulduğun gibi bırak & - tarihi eserlere, flora ve faunaya dokunulmamalıdır. \\
\hline Kamp ateşi etkilerini en aza indir & $\begin{array}{l}\text { - kamp ateşi çukurları kullanılmalıdır. } \\
\text { - aydınlatma ve yemek yapmak için soba/fener kullanılmalıdır. }\end{array}$ \\
\hline Habitata sayg1 gösterilmeli & $\begin{array}{l}\text { - besinler hayvanlardan uzak tutulmalıdır. } \\
\text { - uzaklan gözlem yapılmalıdır. }\end{array}$ \\
\hline Diğer ziyaretçilere saygı duyulmalı & $\begin{array}{l}\text { - gürülttüden kaçınılmalıdır. } \\
\text { - diğer gruplardan uzakta kamp yeri seçilmelidir. }\end{array}$ \\
\hline
\end{tabular}

\section{Sonuç}

Doğada yapılan etkinliklerin ekonomik, sağlığı koruyucu, kültürel etkilerinden uzun süre yararlanmak için, çevresel uyumun sağlanması gerekmektedir. Sürdürülebilirlik uygulamalarında hedeflenen amaç, mutlak koruma alanlarında yer alan kaynak değerlerinin korunması ve bozulmadan gelecek nesillere aktarılmasıdır. Doğayı etkilemek yerine doğa ile uyumlu olmayı hedef alan ve 
doğaya zarar vermeksizin ondan faydalanmaya çalışan bir yaklaşımın benimsenmesi gerekmektedir. $\mathrm{Bu}$ ise doğada yapılan etkinliklerin hammaddesinin korunması anlamına gelmektedir. Orman dokusuna sahip alanların ve dağların yoğun kullanımdan olumsuz yönde etkilendiği açıkça görülmüştür. $\mathrm{Bu}$ etkileri ortadan kaldırmak için aşağıdaki sürdürülebilirlik ilkelerine uyulması gerekmektedir:

- Biyolojik çeşitliliğin korunmasına yönelik hukuksal ve kurumsal düzenlemeler yapılması.

- Endemik ve tehlike altındaki flora ve fauna türleri ile bunların yaşama ortamlarının korumasına yönelik yönetim planları hazırlanması.

- Doğal kaynakların korunması ve sürdürülebilir kullanımı için toplumun her seviyesinde doğa koruma kavramları ve prensipleri ile ilgili eğitim sağlanması.

- Tüm korunan alan kullanıcıları ile işbirliği yapılarak halkın çevre korumaya ilişkin bilincinin arttırılması.

- Kaynakların sürekli ve dengeli kullanımı sağlanmalıdır; doğal sosyal ve kültürel kaynaklar, koruma-kullanma dengesi sağlanarak kullanıma açılmalıdır (Demirayak, 2002).

- Aşırı tüketim ve atık miktarı azaltılmalıdır; çevresel tahribatın restorasyon maliyeti, atık miktarı ve aşırı tüketim azaltılmalıdır.

- Planlama ile doğada yapılan etkinliklerin gelişimi bütünleştirilmelidir; turizm, ulusal ve yerel stratejik planlama ve çevresel etki değerlendirme yapısı altında geliştirilmelidir.

- Çeşitlilik korunmalıdır; doğal, sosyal ve kültürel çeşitlilik korunmalı ve değerleri arttırılmalıdır.

- Yerel toplumla sürekli bir iletişim sağlanmalıdır; sürdürülebilirlik ilke ve politikalarından yerel toplum bilgilendirilmeli ve onların desteği sağlanmalıdır.

- Sürekli inceleme ve analiz çalışmaları yapılmalıdır; etkili veri toplama ve analizleri ile araştırma devam ettirme ve izleme çalışmaları yapılarak, ortaya çıkan sorunlara hemen çözümler geliştirilmesi sağlanmalıdır (Yıldız ve Kalağan, 2008).

- Doğada yapılacak olan motor yarışları, bisiklet yarışları, kampçılık gibi etkinlikler tasarlanırken bulunulan bölgenin doğal şartlarına (iklim, toprak, fauna, flora, topografik durum, vb.) zarar vermeyecek nitelikte planlanmalıdır.

- Doğada yapılan moto-kros, su kayağı, araba yarışı gibi dallarda hava kirliği, toprak kirliliği ve bunlardan kaynaklı su kirliliğini en aza indirmek için benzinli ya da dizel araçlar yerine doğal gaz ya da güneş enerjisi ile çalışan araçlar kullanılmalıdır.

- Spor alanlarında zirai ilaçların kullanımını azaltmak ve uzaklaştırmak flora ve fauna üzerindeki baskıyı azaltırken yer altı ve yer üstü sularının da korunmasına yardımcı olur (Chernushenko vd., 2001).

- Daha iyi bir ulaşım planın yapılması özel araç ihtiyacının azalmasını sağlarken, trafik sıkışıklığının azaltır. Bu durum da yeni yollar ve araba park yerlerinin yapılması gerekmez. Böylelikle gürültü, hava kirliliği, doğal kaynak tüketimi ve yeşil alan kayıpları engellenebilir.

Sonuç olarak doğada yapılan etkinlikler yukarı da bahsedildiği gibi sadece doğa sporları ile sınırlı kalmamaktadır. Bu çok çeşitli etkinliklerin uygulama prensiplerini devlet ve özel kuruluşlar, organizasyonlar ve katılımcılar sürekli denetim altında tutarak çevresel sürdürülebilirliğe destek vermelidirler.

\section{Kaynaklar}

Anonim 2008. IOC Spor, Çevre ve Sürdürülebilir Gelişme Rehberi. Çeviren TMOK. TMOK Yayınları. Anonymous 2009. Queensland Outdoor Recreation Federation (QORF) \& Outdoors Queensland.

Australia. Sustainable Recreation. http://www.qorf.org.au/01_cms/details.asp?ID=358.

Aslan, Z. ve Aktaş, G. 1994. Turizm Açısından Çevre Sorunlarına Genel Bir Yaklaşım. Çevre Dergisi. Nisan, Mayis, Haziran,11: 43-45. www.ekolojidergisi.com.tr/resimler/11-10.pdf.

Bentley, T., Page, S. and Laird, I., 2001. Accidents in The New Zeland Adventure Tourism Industry. Safety Science. 38: 31-48. 
Broadhurst, R. 2001. Managing Environments for Leisure and Recreation. Routledge, Taylor \& Francis Group, London.

Carvalho, O. G. 2001. Sustainable Development: Is it Achievable within The Existing International Political Economy Context? Sustainable Development, May:9: 61-73.

Chernushenko, D., van der Kamp, A. and Stubbs, D. 2001. Sustainable Sport Management: Running and Environmentally Socially and Economically Responsible Organization. Green \& Gold Inc., Ontorio, Canada.

Cordes, K. and Ibrahim, H. M. 1999. Aplication in Recreation \& Leisure for Today and Future. Second Edition, WCB / McGraw-Hill, Boston.

Çevik, S. 1999. Çevre Konularına Genel Bir Bakış. Tüketici Bülteni. TSE Yayınları. Ankara

Demirayak, F. 2002. Biyolojik Çeşitlilik-Doğa Koruma ve Sürdürülebilir Kalkınma. TÜBİTAK Vizyon 2023 Projesi Çevre ve Sürdürülebilir Kalkınma Paneli. Aralık, 2002, Ankara. http://www.tubitak.gov.tr/tubitak_content_files/vizyon2023/csk/EK-14.pdf.

Demirhan, G. 2003. Doğa Sporlarına İlişkin Riskin Algılanması. Spor Bilimleri Dergisi. 14 (1): 1-13.

Dinç, S.C. 2008. Doğa Sporları Ekinliklerine İliş̧in Liderlik Ölçeğinin Geliştirilmesi. H.Ü. Sağlık Bilimleri Enstitüsü, Yayınlanmamış Doktora Tezi.

Ewert, A. 1999. Outdoor Recreation and Natural Resource Management: An Uneasy Alliance. Parks \& Recreation, 34(7): 58-67.

Ewert, A. and Hollenhorst, S. 1995. Adventure Recreation and Its Implication for Wilderness. International Journal of Wilderness, 3(2), 21-26.

Fresque, J. and Plummer, R. (2009). Accounting for Consumption Related to Outdoor Recreation: An Application of Ecological Footprint Analysis. Leisure/Loisir, 33(1): 589-614.

Gladwin , T., Kennely J. and Krause S. T. 1995. Shifting Paradigms for Sustainable Development: Implications for Management Theory and Research. Academy of Management Review, 20 (4): 874-907.

Goldsmith, E. B. 2000. Resource Management for Individuals and Families. Wadswarth, Thomson Learning U.S.A.

Kaya, L.G. and Smardon, R. 2001. Sustainable Tourism Development: The Case Study of Antalya, Turkey. U.S. Dept. of Agriculture, Forest Service, Northeastern Research Station, 2001. General Technical Report NE: 222-227.

Kuntay, O. 2004. Sürdürülebilir Turizm Planlaması. Alp Yayınevi: 147. Ankara.

Mazurkiewicz P. 2005. Corporate Environmental Responsibility: Is a Common. CSR Framework Possible? World Bank Discussion Paper. http://siteresources.worldbank.org/EXTDEVCOMMENG/Resources/csrframework.pdf.

Nemli, E. 2007. Sürdürülebilir Gelişme: Ekonomi ile Çevre Arasındaki Denge, Sunum, İstanbul, Kalder-Çevre Uzmanlık Grubu, http://www.kalder.org.tr.

Priest, S., and Gass, M. 1997. Effective Leadership in Adventure Programming. Champaign, IL: Human Kinetics.

Somuncu, M. 2004. Dağcllık ve Dağ Turizmindeki İkilem: Ekonomik Yarar ve Ekolojik Bedel. Coğrafi Bilimler Dergisi, 2 (1):1-22.

Uluocak, U. ve Köksal, A. 1998. Dağcılık Tarihinde Etik Tartışmalar. I. Doğa Sporları ve Bilim Seтроzуити. Bildiriler Kitabı: 15-16, 23-24 Kasım 1998, Ankara.

WCED 1987. World Commission on Environment and Development, Our Common Future: The Brundtland Report. Oxford University Press, Oxford.

Wheeler, S. 2004. Planning for Sustainability: Toward Livable, Equitable, and Ecological Communities. Londra ve New York: Routledge.

Yıldız, Z., ve Kalağan, G. 2008. Alternatif Turizm Kavramı ve Çevresel Etkileri. Yerel Siyaset, Kasım, 35: 42-44. 